\title{
EXTENSIONS OF A BONNESEN-STYLE INEQUALITY TO MINKOWSKI SPACES
}

\author{
Horst MARTini AND ZOKHRAB MustaFAeV
}

\begin{abstract}
Various definitions of surface area and volume are possible in finite dimensional normed linear spaces (= Minkowski spaces). Using a Bonnesen-style inequality, we investigate the ratio of the Holmes-Thompson surface area of the unit ball to its volume. In particular, in the planar case a stronger lower bound for this ratio is established when the area is defined in the sense of Holmes-Thompson, or is given by the definition of mass. From this we obtain some (characteristic) properties of Radon curves.
\end{abstract}

\section{Mathematics subject classification (2000): 52A10, 52A21, 52A40, 46B20.}

Key words and phrases: Benson area, Busemann area, Bonnesen inequality, convex body, HolmesThompson area, isoperimetrix, mass area, Minkowski plane, mixed volume, normed linear space, Petty's conjectured projection inequality, projection body, Radon curve, relative inner and outer radii, tangent body.

\section{REFERENCES}

[1] Alvarez, J.C., AND Duran, C., An Introduction to Finsler Geometry, Notas de la Escuela Venezolana de Mathematicas, 1998.

[2] AlvareZ, J.C. AND Thompson, A.C., On the perimeter and area of the unit disc, Amer. Math. Monthly 112 (2005), 141-154.

[3] AlvareZ, J.C. AND Thompson, A.C., Volumes in normed and Finsler spaces, A sampler of RiemannFinsler geometry, 1-48, Math. Sci. Res. Inst. Publ. 50, Cambridge Univ. Press, Cambridge, 2004.

[4] Bonnesen, T. And Fenchel, W., Theory of Convex Bodies, BCS Associates, Moscow, Idaho USA, 1987.

[5] BRANNEN, N.S., Volumes of projection bodies, Mathematika 43 (1996), 255-264.

[6] Diskant, V.I., A generalization of Bonnesen's inequalities, Soviet Math. Dokl. 14 (1973), 1728-1731 (transl. of Dokl. Akad. Nauk SSSR 213 (1973), no 3).

[7] DüVELMEYER, N., A new characterization of Radon curves via angular bisectors, J. Geom. 80 (2004), 75-81.

[8] Favard, J., Sur les corps convexes, J. Math. Pures. Appl. (9) 12 (1933), 219-282.

[9] Flanders, H., A proof of Minkowski's inequality for convex curves, Amer. Math. Monthly 75 (1968), 581-593.

[10] Gage, M., Positive centers and the Bonnesen inequality, Proc. Amer. Math. Soc. 110 (1990), 1041-1048.

[11] GRUBER, P.M., Stability of Blaschke's characterization of ellipsoids and Radon norms, Discrete Comput. Geom. 17 (1997), 411-427.

[12] Holmes, R.D., AND ThOMPSON, A.C., $N$-dimensional area and content in Minkowski spaces, Pacific J. Math. 85 (1979), 77-110.

[13] LaugwitZ, D., Konvexe Mittelpunktsbereiche und normierte Räume, Math. Z. 61 (1954), 235-244.

[14] LuTwaK, E., On a conjectured inequality of Petty, Contemp. Math. 113 (1990), 171-182.

[15] Martini, H., AND MuSTAFAEV, Z., Some applications of cross-section measures in Minkowski spaces, Period. Math. Hungar. 53 (2006), 185-197.

[16] Martini, H. AND SwANEPOEL, K.J., Equiframed curves - a generalization of Radon curves, Monatsh. Math. 141 (2004), 301-314.

[17] Martini, H. And Swanepoel, K.J., Antinorms and Radon curves, Aequationes Math. 71 (2006), 110-138. 
[18] Martini, H., Swanepoel, K.J., Weiss, G., The geometry of Minkowski spaces - a survey. Part I, Expositiones Math. 19 (2001), 97-142.

[19] Martini, H., SwANePOEL, K.J., Weiss, G., The Fermat-Torricelli problem in normed planes and spaces, J. Optim. Theory Appl. 115 (2002), 283-314.

[20] Mustafaev, Z., The ratio of the length of the unit circle to the area of the unit disk in Minkowski planes, Proc. Amer. Math. Soc. 133 (2005), 1231-1237.

[21] Osserman, R., Bonnesen-style isoperimetric inequalities, Amer. Math. Monthly 86 (1979), 1-29.

[22] REISNER, S., Zonoids with minimal volume-product, Math. Z. 192 (1986), 339-346.

[23] Sangwine-Yager, J.R., Bonnesen-style inequalities for Minkowski relative geometry, Trans. Amer. Math. Soc. 307 (1988), 373-382.

[24] SCHÄFFER, J.J., Geometry of Spheres in Normed Spaces, Marcel Dekker, Inc., New York-Basel, 1976.

[25] SCHNEIDER, R., Geometric inequalities Poisson processes of convex bodies and cylinders, Results Math. 11 (1987), 165-186.

[26] SCHNEIDER, R., Convex Bodies: The Brunn-Minkowski Theory, Encyclopedia of Mathematics and its Applications, Vol. 44, Cambridge University Press, Cambridge, 1993.

[27] TAMÁssy, L., Über ein Problem dez zweidimensionalen Minkowskischen Geometrie, Ann. Polon. Math. $9(1960 / 61), 39-48$.

[28] Thompson, A.C., Minkowski Geometry, Encyclopedia of Mathematics and its Applications, Vol. 63, Cambridge University Press, Cambridge, 1996. 